\title{
INDUCTION DEVICE FOR HEAT TREATMENT OF WELDED JOINTS OF RAILWAY RAILS
}

\author{
E.A. PANTELEJMONOV and R.S. GUBATYUK \\ E.O. Paton Electric Welding Institute, NASU \\ 11 Kazimir Malevich Str., 03680, Kiev, Ukraine. E-mail: office@paton.kiev.ua
}

\begin{abstract}
The paper studies the design peculiarities of induction device for heat treatment of welded joints of railway rails and gives the results of its testing. The device uses the inductors with magnetic cores and matching transformers, developed and manufactured at PWI. The inductors are located opposite one another from rail sides. Inductive wire of the inductor is divided for two parallel conductors, which follow the shape of rail surface, surround part of running surface, inner edge of rail head, rail web and part of rail flange with increased air gaps in area of rail web and blades. The magnetic cores are located over rail head running surface, inner edges of head, web and lower surface of rail flange. Testing of induction device at $2.4 \mathrm{kHz}$ current frequency showed uniform distribution of temperature field in rail section and absence of overheating of rail blades. Heating of rail zone of $50-55 \mathrm{~mm}$ width to $850-910{ }^{\circ} \mathrm{C}$ temperature took $140 \mathrm{~s}$. Nominal power of supply source is $90 \mathrm{~kW} .7$ Ref., 4 Figures 4.
\end{abstract}

Ke y words : rails, rail welded joints, heat treatment, induction heating, inductor

Heat treatment of the welded joints of railway rails, produced with resistance butt welding, is used for providing structural zonal homogeneity after welding, balance of hardness of metal of rails head, elimination of unfavorable diagram of internal residual stresses of welded joint metal $[1,2]$. A process of heat treatment includes heating of welded joint zone and further quenching of running surface of rail head by means of forced cooling with air-water mixture or compressed air. Currently, heat treatment of the welded joints of rails is carried out, mainly, using induction units of UIN-001 type of different modification. The main elements of the unit are a system of inductors, control block, quenching block and high-frequency power source of $100 \mathrm{~kW}$ power and current frequency $8.0-16.0 \mathrm{kHz}$. The system of inductors includes two similar electrically connected multirun inductors without magnetic cores. The heating temperature for heat treatment of welded joints of rails of R65 type at UIN-001 unit makes $850-950{ }^{\circ} \mathrm{C}$, heating time is $240 \mathrm{~s}$ from welding heat and $360 \mathrm{~s}$ from workshop temperature $[3,4]$.

One of the ways to increase efficiency of induction heating equipment for heat treatment of the welded joints of rails is improvement of inductor design. A task of the inductors is to reduce the of time of welded joints heating in order to increase efficiency of rail bar production lines, provide uniform distribution of temperature field along rail section and eliminate rail elements overheating.

It is known that the magnetic cores $[5,6]$ promote increase of level of electromagnetic coupling

(C) E.A. PANTELEJMONOV and R.S. GUBATYUK, 2016 of current in the inductors with eddy-currents being inducted in the heated part, and, respectively, rise of efficiency and coefficient of power of inductor-part induction system. Application of the magnetic cores in the inductors allows distributing power delivered to the welded joint taking into account difference in mass of metal of head, web and flange of the rail as well as solving the problem of head center heating and place of transfer of the rail flange into the web due to the peculiarities of heating of complex shape parts with high frequency currents.

Present work describes the peculiarities of inductor design and gives the results of testing of the induction device for heat treatment of the welded joints of railway rails. The inductors with magnetic cores and matching transformers, developed and manufactured

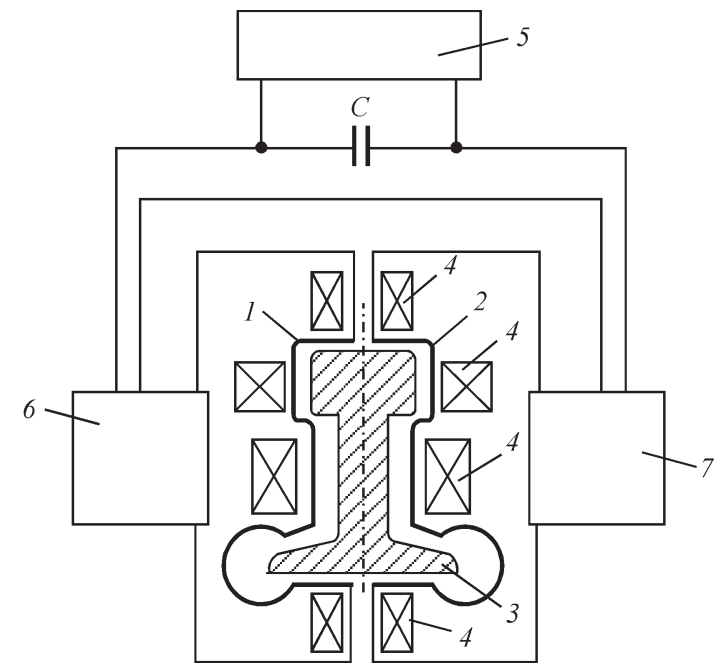

Figure 1. Scheme of induction device (descriptions $1-7$ see in the text) 


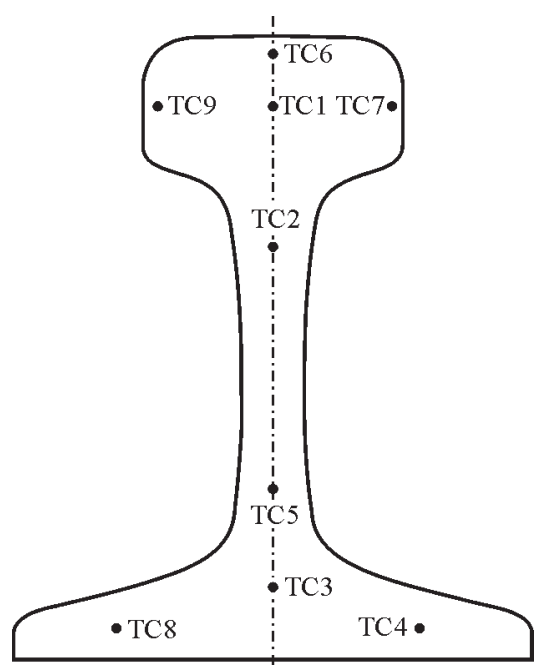

Figure 2. Scheme of location of thermal-electric converters TC1TC9 in rail section (see designations in the text)

at PWI, are used in the device. Nominal frequency of current is $2.4 \mathrm{kHz}$.

Induction device (Figure 1) consists of inductors 1 and 2 of similar design. The inductors are located opposite one another from rail 3 side surfaces. Inductive wire of the inductor is divided for two parallel conductors, follow the shape of rail surface, surround part of running surface, inner edge of rail head, rail web and part of rail flange with increased air gaps in area of rail web and blades. Conduct buses of the inductors over the head running surface are equipped with the channels for passing a pyrometer beam. The different length magnetic cores 4 are installed over the head running surface, inner edges of rail head, web and lower surface of rail flange [7]. Matching transformers 6 and 7 are used for connection of inductors to thyristor frequency converter 5 .

Efficiency of the induction device was investigated in heating of zone of R65 type rail. Infrared pyrometer Optris CSLT15 was used for measurement of temperature on running surface of rail head. A distance from pyrometer to running surface makes $130 \mathrm{~mm}$. Temperature of metal in rail section was controlled with chromel-alumel thermal-electric converters TC1-TC9 (TC1 - along symmetry axis at $20 \mathrm{~mm}$

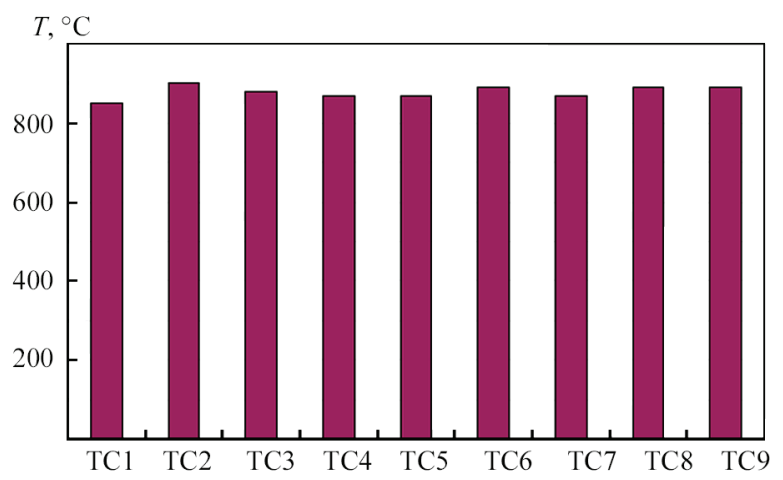

Figure 4. Histogram of temperature in points of rail section during 140 s heating time

depth from running surface; TC2, TC3, TC5 - along symmetry axis at 120,20 and $50 \mathrm{~mm}$ distance, respectively, from flange lower surface; TC4 and TC8 - at $10 \mathrm{~mm}$ depth from flange lower surface and $32 \mathrm{~mm}$ from blade edges; TC6 - along symmetry axis at $3 \mathrm{~mm}$ depth from running surface; TC7, TC9 - in center of inner edges at $3 \mathrm{~mm}$ depth) (Figure 2).

Tests of the induction device showed that heating of rail zone from $20{ }^{\circ} \mathrm{C}$ temperature to temperature on head running surface $850{ }^{\circ} \mathrm{C}$ (Figure 3,a) was carried out for $60 \mathrm{~s}$. The nominal power of frequency converter is $90 \mathrm{~kW}$. Width of heat affect zone makes $50-55 \mathrm{~mm}$. The rate of heating of head running surface to temperature of magnetic transformation point makes around $17.5^{\circ} \mathrm{C} / \mathrm{s}$. The rate of heating on head running surface reduces to $1{ }^{\circ} \mathrm{C} / \mathrm{s}$ with metal loss of magnetic properties and rise of depth of current penetration. The time of heating reduces to $40 \mathrm{~s}$ in heating of rail zone from $250{ }^{\circ} \mathrm{C}$ temperature to temperature on head running surface $850^{\circ} \mathrm{C} / \mathrm{s}$ (Figure $3, b$ ) and nominal power of frequency converter $90 \mathrm{~kW}$. Heating of rail zone from $250{ }^{\circ} \mathrm{C}$ temperature was simulated by a process of heat treatment of the welded joints of rails from welding heat in process lines of rail bar production.

Distribution of the temperature field in rail section in heating of rail zone from $20^{\circ} \mathrm{C}$ during $140 \mathrm{~s}$ are reflected by dependencies, given in Figure 4. Temperature of head inner edges is $870-890{ }^{\circ} \mathrm{C}$ (TC7,
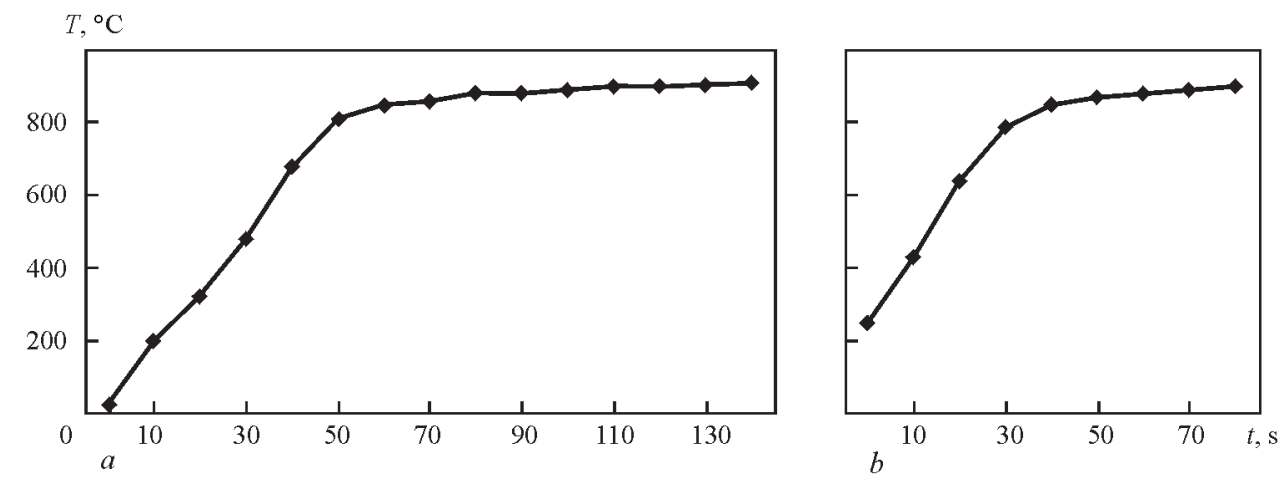

Figure 3. Time dependencies of temperature on running surface of rail head in heating of rail zone from $20(a)$ and from $250{ }^{\circ} \mathrm{C}(b)$ 
TC9), that of web makes $870-890{ }^{\circ} \mathrm{C}(\mathrm{TC} 2$, TC5), it is $880{ }^{\circ} \mathrm{C}(\mathrm{TC} 3)$ at $20 \mathrm{~mm}$ depth from lower surface of flange along rail symmetry axis and $870-890{ }^{\circ} \mathrm{C}$ for rail flange (TC4, TC8). Time of holding of head running surface at temperature more than $850{ }^{\circ} \mathrm{C}$ is around $80 \mathrm{~s}$. A temperature difference between running surface (Figure 3,a) and center of head (TC1, Figure 1) is not more than $50-60{ }^{\circ} \mathrm{C}$. No overheating of rail blades is present. The temperature in place of flange to rail web transfer is $880-890{ }^{\circ} \mathrm{C}$ (TC3, TC5).

\section{Conclusions}

1. The induction device for heat treatment of the rail welded joints includes the inductors with magnetic cores and matching transformers, developed and manufactured at PWI. The inductors differ by design of inductive wire and location of magnetic core relatively to rail elements.

2. Uniform distribution of the temperature field in rail section and absence of rail blades overheating were reached in process of testing of the induction device at current frequency $2.4 \mathrm{kHz}$. Heating of the rail zone of 50-55 mm width to $850-910{ }^{\circ} \mathrm{C}$ temperature was performed for $140 \mathrm{~s}$. Nominal power of supply source is $90 \mathrm{~kW}$. It is necessary to note a reduction of time of heating in comparison with ITTZ-250/2.4 and UIN-001 units, which are used for heat treatment of the welded joints of rails under track and workshop conditions.

1. Genkin, I.Z. (2003) Heat treatment of rail welded joints in induction units. The Paton Welding J., 9, 38-41.

2. Nesterov, D.K., Sapozhkov, V.E., Levchenko, N.F. et al. (1990) Heat treatment of rail steel using induction heating. Metallovedenie i Termicheskaya Obrabotka Metallov, 8, 30-34.

3. Rezanov, V.A., Fedin, V.M., Bashlykov, A.V. et al. (2013) Differential quenching of rail welded joints. Vestnik VNIIZhT, 2, 28-33.

4. Fedin, V.M. (2005) Development of new technological equipment for restoration of used rails. Ibid., 4, 22-25.

5. Slukhotsky, A.E., Ryskin, S.G. (1974) Inductors for induction heating. Leningrad: Energiya.

6. Pismenny, A.S., Pantelejmonov, E.A., Prokofiev, A.S. et al. (2000) Design of an inductor with a magnetic core for heating flat surfaces. The Paton Welding J., 11, 41-45.

7. Pantelejmonov, E.A. Induction device for heat treatment of rail welded joints. Pat. 109123 UA. Int. Cl. K C 21D1/10. Publ. 10.08.2016. 